\title{
OPTIMIZATION OF A FLOW CYTOMETRY METHOD FOR THE APPROACH OF LIQUID BIOPSY AS A THERAPY MODULATION TOOL IN PATIENTS WITH COLORECTAL CANCER
}

\author{
ARIANA HUDIȚA ${ }^{1 \#}$, VLAD IOANA-LAVRIC ${ }^{1 \#}$, ANCA ZAMFIR $^{2 \#}$, LAURA BUBURUZAN $^{2 \#}$, \\ OCTAV GINGHINA ${ }^{3 \# *}$, CAROLINA NEGREI ${ }^{4 *}$, GEORGE TRAIAN ALEXANDRU BURCEA \\ DRAGOMIROIU $^{5 *}$, MARIETA COSTACHE $^{1 \#}$, CARMEN ARDELEANU $^{2 *}$, EUGEN RADU $^{6 *}$,

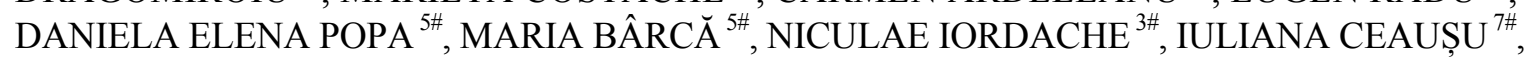 \\ BIANCA GĂLĂȚEANU ${ }^{1 \#}$
}

\author{
${ }^{I}$ Department of Biochemistry and Molecular Biology, Faculty of Biology, University of Bucharest, 91-95 Splaiul Independenței, \\ 050095, Bucharest, Romania \\ ${ }^{2}$ OncoTeam Diagnostic, 313A Splaiul Unirii Street, 030138, Bucharest, Romania \\ ${ }^{3}$ Department of Surgery, "Sf. Ioan" Clinical Emergency Hospital, Faculty of Dental Medicine, "Carol Davila” University of \\ Medicine and Pharmacy, 13 Vitan Bârzești Road, 042122, Bucharest, Romania \\ ${ }^{4}$ Departament of Toxicology, Faculty of Pharmacy, "Carol Davila" University of Medicine and Pharmacy, 6 Traian Vuia \\ Street, 020956, Bucharest, Romania \\ ${ }^{5}$ Departament of Drug Control, Faculty of Pharmacy, "Carol Davila” University of Medicine and Pharmacy, 6 Traian Vuia \\ Street, 020956, Bucharest, Romania \\ 6 "Molimagex" Molecular Biology and Pathology Research Lab, University Hospital Bucharest, 169 Splaiul Independenței \\ Street, 050098 Bucharest, Romania \\ ${ }^{7}$ Faculty of Medicine, University of Medicine and Pharmacy "Carol Davila", Department of Obstetrics and Gynaecology, \\ "Dr. I. Cantacuzino” Hospital, 5-7 Ion Movilă Street, Bucharest, Romania
}

*corresponding author: octavginghina@gmail.com

\#All authors have equal contribution.

Manuscript received: January 2018

\begin{abstract}
Personalized medicine in oncology aims to tailor a particular dynamic treatment for the individual, starting from the diagnostic throughout therapy. To guide the appropriate treatment decisions, liquid biopsy is being used as a real time monitoring analysis targeting the detection and analysis of: (i) circulating tumour cells that shed from the tumours and circulate through the blood stream, (ii) circulating tumour DNA (cell free DNA originated from apoptotic and necrotic tumour cells) and (iii) exosomes of tumour origin. Many techniques were developed to isolate cells of epithelial origin in whole blood based on the expression of cell-surface markers like EpCAM and panCK. However, due to their low number (1 10 cells $/ \mathrm{mL}$ of whole blood) as compared to normal blood cells, enrichment strategies are to be developed for optimum results. In this context, the aim of this study was to develop a flow cytometry protocol to detect the circulating tumour cells in patients with colon cancer, with high impact on therapy modulation.
\end{abstract}

\section{Rezumat}

Medicina personalizată în oncologie își propune să individualizeze un anumit tratament, în mod dinamic, pornind de la diagnostic, pe tot parcursul terapiei. În acest sens, biopsia lichidă este utilizată ca o analiză de monitorizare în timp real, care vizează detectarea și analiza: (i) celulelor tumorale circulante, eliberate din tumori epiteliale, (ii) ADN tumoral circulant (ADN liber provenit din celule tumorale apoptotice şi necrotice) şi (iii) exozomi de origine tumorală. Au fost dezvoltate numeroase tehnici pentru izolarea celulelor de origine epitelială în sânge pe baza expresiei markerilor de suprafață EpCAM și panCK. Cu toate acestea, datorită numărului scăzut de celule tumorale circulante $(1-10$ celule/mL de sânge $)$ în raport cu numărul celulelor sanguine normale, este necesară dezvoltarea unor strategii de concentrare. În acest context, scopul acestui studiu a fost dezvoltarea un protocol de citometrie în flux pentru detecția celulelor tumorale circulante la pacienții cu cancer de colon, cu impact asupra modulării terapiei.

Keywords: liquid biopsy, flow cytometry, circulating tumour cells, EpCAM, CD45 depletion

\section{Introduction}

Currently, cancer is a major cause of death worldwide, which has led to increasing interest in finding new and more effective therapies and monitoring approaches.
Moreover, considering that tumours might alter their molecular genotype over time as a result of treatment, historical biopsy data might lose their relevance. In this regard, personalized medicine has gained ground in 
FARMACIA, 2018, Vol. 66, 5

recent years [1] and aims to tailor a particular dynamic treatment for the individual, starting from the diagnostic throughout therapy. To guide the appropriate treatment decisions, a real time monitoring analysis would be mandatory in order to accurately characterize at any time the tumour's particular molecular profile. Not only this, but also the impediments caused by the tissue biopsy harvest have led to the development of the so called: "liquid biopsy", a non-invasive analysis of the peripheral blood, that allows repeat sampling to monitor both the presence of the circulating tumour cells and the genetic changes over time without the need for a tissue biopsy $[2,3]$.

Liquid biopsies target the detection and analysis of three types of biomarkers: (i) circulating tumour cells that shed from the tumours and circulate through the blood stream, potentially initiating metastatic lesions development, (ii) circulating tumour DNA (cell free DNA originated from apoptotic and/or necrotic tumour cells) and (iii) exosomes of tumour origin (cell membrane covered small vesicles continuing functional biomolecules of tumour origin such as proteins, RNA or DNA) [4, 5]. Such ctDNA fragments contain considerable information that allows for more accurate characterization of the cancer type and, moreover, for complex analysis by next generation sequencing [6]. More, tumour-originated exosomes are thought to be a means to prepare a suitable microenvironment of pre-metastatic niches [7].

CTCs have been detected in various metastatic carcinomas [8,9]. However, considering that $1 \mathrm{ml}$ of whole blood contains $\sim 7 \times 10^{6}$ white blood cells and $\sim 5 \times 10^{9}$ red blood cells, their low number $(\sim 1-10$ CTCs per $\mathrm{mL}$ of whole blood) [10] makes them very difficult to be detected. Many affinity - based techniques such as the CellSearch assay [11] (the only FDA approved method of detecting CTCs in breast cancer), the Herringbone - CTC chip $[12,13]$, and flow cytometry - based approaches $[14,15]$ were developed to isolate cells based on the expression of cell-surface markers. Independent of the technique used, the detection of tumour cells by liquid biopsy targets mainly the epithelial cell adhesion molecule (EpCAM) [16] and the cytokeratins (panCK) [17] from the population of nucleated cells in the blood. Many of these selection technologies are criticized for their reliance on cell-surface expression of EpCAM to capture (and define) CTCs because some tumours down-regulate expression of this marker during EMT $[18,19]$. Additional markers such as: HER-2 [20, 21], EGFR [22, 23], MUC-1 [24, 25] or SOX-2 [26, 27] could be relevant for targeting colon cancer cells.

In this context, the current study aims to develop a circulating colorectal tumour cells detection protocol by using flow cytometry. For this, according to the above state of the art we selected a colorectal tumour specific antigens panel and validated it both by confocal microscopy and flow cytometry on HT-29 colorectal adenocarcinoma cells. Next, we developed an HT-29 enrichment protocol from blood samples by comparing the outcomes of the positive and negative selection strategies after fluorescent staining with the appropriate antibodies and flow cytometry analysis of the samples.

\section{Materials and Methods}

\section{Cell culture model and blood samples}

HT-29 human colon adenocarcinoma cells (ATCC American Type Culture Collection - HTB-38) were grown in standard conditions of culture $\left(37^{\circ} \mathrm{C}\right.$, under humidified atmosphere and $5 \% \mathrm{CO}_{2}$ ) in Dulbecco's modified Eagle`s Medium (DMEM), supplemented with $10 \%$ foetal bovine serum (FBS) and $1 \%$ cell culture specific antibiotic/antimycotic mix.

For propagation, cells were detached from the monolayers by enzymatic treatment with trypsin/EDTA and split 1:3, two times per week.

The blood samples were harvested by qualified medical staff and all the medical procedures were performed in compliance with the Helsinki Declaration. The blood samples were provided by LotusMed under agreement with OncoTeam Diagnostic for research purposes. All the in vitro studies presented in this paper were approved by the University of Bucharest Ethical Committee (reference number: 1/28.02.2018).

Tumour specific antigens panel validation

Based on the literature screening we selected the following target antigens in order to detect colorectal tumour cells in the peripheral blood of the patients already diagnosed with this pathology: EpCAM, Her-2, EGFR, panCK, c-MET, MUC-1 and Sox-2. Considering both the fluorochromes spectral overlap and the configuration of our instruments (Carl Zeiss LSM710 confocal microscope and Beckman Coulter CytoFLEX flow cytometer), we have designed the antibodies panel presented in Table I.

Table I

Antibodies panel for HT-29 adenocarcinoma cells detection

\begin{tabular}{|c|c|c|}
\hline & Antigen & Fluorochrome \\
\hline 1 & EpCAM & FITC \\
\hline 2 & Her-2 & PerCp Cy 5.5 \\
\hline 3 & EGFR & APC \\
\hline 4 & panCK & AF647 \\
\hline 5 & c-MET & AF700 \\
\hline 6 & MUC-1 & AF750 \\
\hline 7 & Sox-2 & PB \\
\hline
\end{tabular}

Furthermore, we subjected to validation by confocal microscopy and flow cytometry this antigens panel on HT-29 adenocarcinoma cells in order to confirm both: (i) the expression of these markers in our in vitro cellular model and (ii) the technical possibility of their detection with the instruments available in our labs. Confocal microscopy validation of antigens panel. HT-29 adenocarcinoma cells were seeded at an initial 
FARMACIA, 2018, Vol. 66, 5

density of $2.5 \times 10^{4}$ cells $/ \mathrm{cm}^{2}$ on coverslips, in 24 wellplates. After $24 \mathrm{~h}$ of culture in standard conditions, the culture medium was removed and the monolayers were washed with PBS twice. Next, the cells were fixed with 4\% para-formaldehyde (PFA) and after a PBS wash step; the cell membrane was permeabilized with $2 \%$ bovine serum albumin (BSA) and $0.1 \%$ Triton X-100 solution. After another PBS wash step, the monolayers were incubated overnight at $4^{\circ} \mathrm{C}$ with the following antibodies solution (each solution was prepared according to the manufacturer's indication): EpCAM-FITC (StemCell Technologies, code: 60136FI), Her-2-PerCp Cy5.5 (Biolegend, code: 324416), EGFR-APC (Biolegend, code: 352906), panCK-AF647 (Santa-Cruz Biotechnology, code: sc-8018-AF647), c-MET-AF700 (Novusbio, code: FAB3582N), MUC-1-AF750 (Novusbio, code: FAB6298S) and Sox-2-PB (Biolegend, code: 656112). The next day, the antibodies solutions were removed and after a PBS wash step, the nuclei of the cells were stained with DAPI for $1 \mathrm{~h}$ at room temperature and darkness. In the end, the monolayers were inspected using the 405, 488 and $543 \mathrm{~nm}$ excitation laser lines of a Zen710 Carl Zeiss confocal microscope. The specimens were observed with a Zeiss 20x 0.5 NA objective and the images were captured and analysed using the Carl Zeiss Zen 2010 software, version 6.0.

Flow cytometry validation of antigens panel. HT-29 adenocarcinoma cells were harvested by enzymatic treatment with trypsin/EDTA solution from the $75 \mathrm{~cm}^{2}$ culture flasks, counted in a Burker-Turk chamber and distributed in analysis tubes $\left(10^{5}\right.$ cells/sample). The cells were fixed using component A from the Fix\& Perm kit (Nordic Mubio, GAS-002), centrifuged and washed with PBS. The permeabilization and staining steps were performed simultaneously by incubating the cells in the component B from the Fix\&Perm kit (Nordic Mubio, GAS-002) containing the following antibodies (the antibodies concentrations were in accordance with the manufacturer's indications): EpCAM-FITC (StemCell Technologies, code: 60136FI), Her-2-PerCp Cy5.5 (Biolegend, code: 324416), EGFR-APC (Biolegend, code: 352906), panCK-AF647 (Santa-Cruz Biotechnology, code: sc-8018-AF647), c-MET-AF700 (Novusbio, code: FAB3582N), MUC-1-AF750 (Novusbio, code: FAB6298S) and Sox-2-PB (Biolegend, code: 656112). Isotype control samples were additionally prepared by using the following antibodies: IgGFITC (Beckman Coulter, code A07795), IgG- PerCp Cy5.5 (Biolegend, code 400149), IgG- APC (Biolegend, code 400121), IgG- AF700 (Novusbio, code IC002N), IgG-AF750 (Novusbio, code IC002S) and IgG-PB (Biolegend, code 400131). After this step, the cells were washed, resuspended in $0.5 \mathrm{~mL}$ PBS and acquired in Cytoflex flow cytometer (Beckman Coulter). All the samples were prepared in triplicate.
Positive selection of HT-29 cells from peripheral blood samples

HT-29 adenocarcinoma cells were harvested by enzymatic treatment from the culture flasks, counted and spiked into a blood sample $\left(10^{6}\right.$ HT-29 cells/ sample) to be isolated by using EasySep ${ }^{\mathrm{TM}}$ Human EpCAM Positive Selection Kit (StemCell Technologies, code 18356). Briefely, $10 \mathrm{~mL}$ of peripheral blood containing HT-29 cells were diluted $1: 1$ with $2 \%$ FBS supplemented DPBS (StemCell Technologies, code 7905 ) in a $50 \mathrm{~mL}$ SepMate $^{\mathrm{TM}}$ tube (StemCell Technologies, code 86450). Lymphoprep gradient density medium (StemCell Technologies, code 7811) was added and then the tube was centrifuged at $1.200 \mathrm{x} \mathrm{g}$ for 10 minutes. The enriched fraction was collected, centrifuged at $300 \mathrm{xg}$ for 10 minutes and the cellular pellet was re-suspended in $1 \mathrm{~mL}$ of cold medium. This cells suspension containing HT-29 cells was added in a $5 \mathrm{~mL}$ round bottom tube and mixed with $100 \mu \mathrm{L}$ Selection Cocktail from the above mentioned kit. After 20 minutes of incubation at $4{ }^{\circ} \mathrm{C}$, $50 \mu \mathrm{L}$ of Magnetic Particles were added and further incubated for another 15 minutes at $4^{\circ} \mathrm{C}$. Next, cold medium was added up to $2.5 \mathrm{~mL}$ (total volume) and the tube was placed into the magnet (StemCell Technologies, code 18000) at room temperature. After 5 minutes, the supernatant was discarded and the resulting cells were re-suspended in cold culture medium and further used for flow cytometry analysis of their phenotype.

Negative selection of HT-29 cells from peripheral blood samples

HT-29 adenocarcinoma cells were harvested by enzymatic treatment from the culture flasks, counted and spiked into a blood sample $\left(10^{6}\right.$ HT-29 cells/ sample) to be isolated by using RosetteSep ${ }^{\mathrm{TM}}$ Human CD45 Depletion Cocktail (StemCell Technologies, code 15122), based on negative selection strategy. Briefly, $10 \mathrm{~mL}$ of peripheral blood containing HT-29 cells were diluted $1: 1$ with $2 \%$ FBS supplemented DPBS (StemCell Technologies, code 7905) in a $50 \mathrm{~mL}$ SepMate $^{\mathrm{TM}}$ tube (StemCell Technologies, code 86450). Lymphoprep gradient density medium (StemCell Technologies, code 7811) containing RosetteSep ${ }^{\mathrm{TM}}$ Cocktail from the depletion kit was added and then the tube was centrifuged at $1.200 \mathrm{x}$ g for 10 minutes. The enriched fraction was collected, and the cells were further used for their phenotype analysis by flow cytometry.

Flow cytometry characterization of the isolated cells All the isolated cells were fixed using component A from the Fix\&Perm kit (Nordic Mubio, GAS-002), centrifuged and washed with PBS. The permeabilization and staining steps were performed simultaneously by incubating the cells in the component B from the Fix\&Perm kit (Nordic Mubio, GAS-002) containing the following antibodies (the antibodies concentrations were in accordance with the manufacturer's indications): 
FARMACIA, 2018, Vol. 66, 5

EpCAM-FITC (StemCell Technologies, code: 60136FI), panCK-AF647 (Santa-Cruz Biotechnology, code: Sc-8018-AF647), MUC-1-AF750 (Novusbio, code: FAB6298S) and CD45-V500 (Becton Dickinson, code 560779). The EpCAM staining was done only for the cells isolated based on the negative selection strategy, as all the cells isolated based on the positive selection strategy were supposed to be EpCAM positive. CD45 staining was performed in order to confirm the depletion of $\mathrm{CD} 45^{+}$cells. After staining, the samples were analysed using a Cytoflex flow cytometer (Beckman Coulter).

Data analysis

All the samples were prepared in 3 biological replicates. The confocal microscopy images were acquired and analysed using the Zen 2010 Software, version 6.0. All the flow cytometry data were obtained and analysed using the CytExpert Software version 2.0.0.153 and Kaluza Software version 1.5a (Beckman Coulter).

\section{Results and Discussion}

One of the main reasons in choosing flow cytometry for the development of a liquid biopsy protocol was the flexibility of selecting the panel of markers of interest. Considering that each tumour cell type could be characterized by a tumour - specific panel of antigens, this flow cytometry protocol could be easily adjusted depending on the cancer type to be detected. However, the major milestone to be overcome in order to validate such a protocol is the detection of the tiny epithelial-like population inside the normal blood cells populations.

In order to achieve this, we developed in this study an in vitro model for the detection of circulating colorectal cancer cells in peripheral blood. For this, we designed a seven colours panel of colorectal specific antigens, we selected the markers expressed in our particular experimental conditions both by confocal microscopy and flow cytometry and we developed an efficient protocol for the recovery of the tumour colorectal cells from peripheral blood.

Confocal microscopy validation of the designed panel of antigens

The monolayers of HT-29 adenocarcinoma cells were double stained for: (i) one of the following antigens of interest: EpCAM, Her-2, EGFR, panCK, c-MET, MUC-1 and Sox2, and (ii) cells nuclei (DAPI staining). The specimens were inspected using the Zeiss 710 Carl Zeiss confocal microscope and a selection of the most relevant images captured with the Zen 2010 software, version 6.0. is presented in Figure 1.
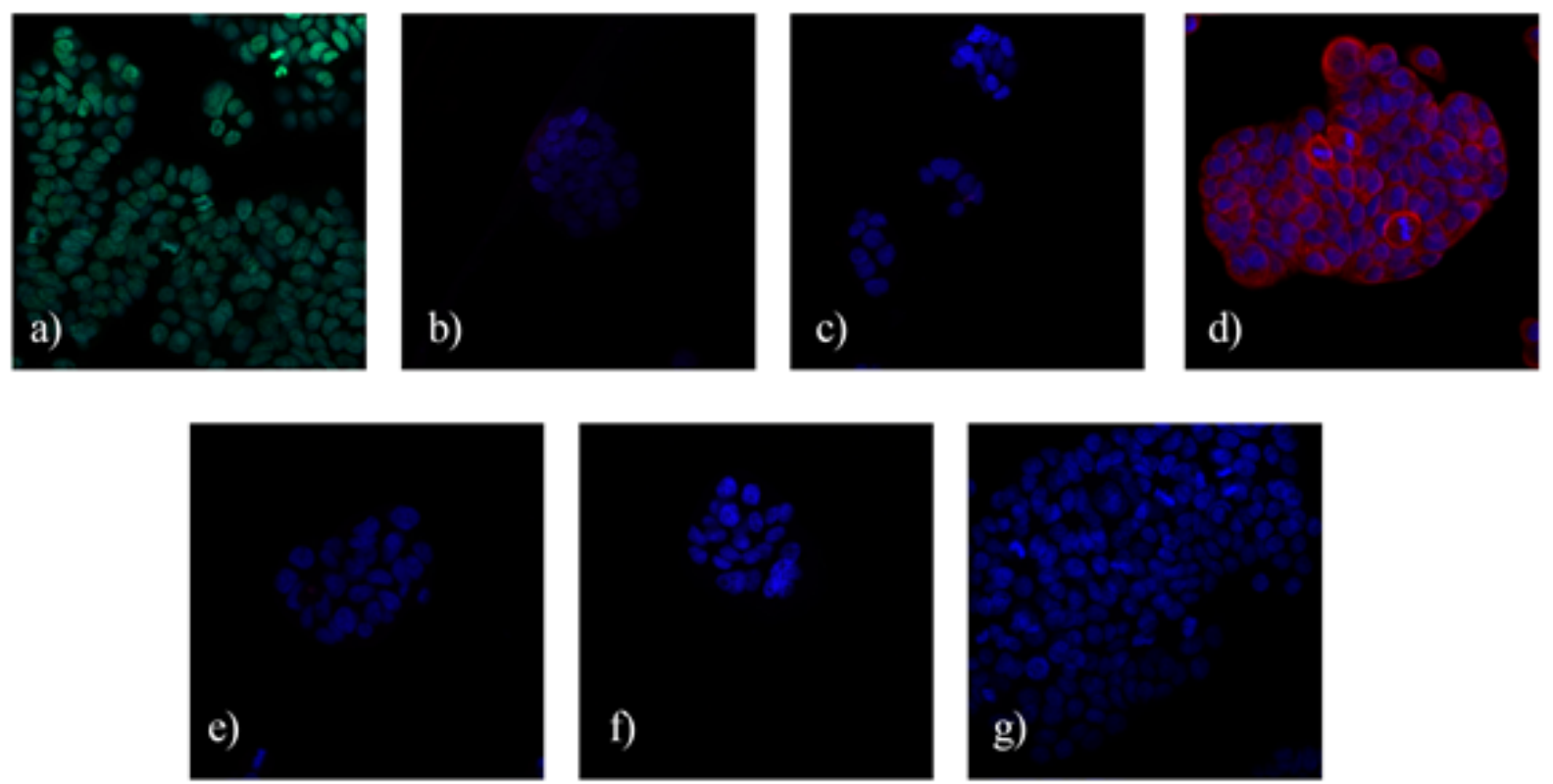

Figure 1.

Confocal microscopy images of HT-26 adenocarcinoma cells stained with a) EpCAM-FITC, b) Her-2-PerCp Cy5.5, c) EGFR-APC, d) panCK-AF647, e) c-MET-AF700, f) MUC-1-AF750, g) Sox-2-PB and DAPI (blue fluorescence) for the nuclei labelling

As shown in Figure 1, our data shows that we were able to identify positive fluorescence signal only for EpCAM and panCK markers, when all the samples displayed a positive staining with DAPI, for the labelling of the nuclei.
Flow cytometry validation of the designed panel of antigens

HT-29 adenocarcinoma cells were stained for each of the following antigens: EpCAM, Her-2, EGFR, panCK, c-MET, MUC-1 and Sox 2 in separate tubes. The corresponding Isotype controls were prepared in order 
FARMACIA, 2018, Vol. 66, 5

to accurately determine the positive fluorescence signal for each antigen. The histograms showing the fluorescence signal on each detector were presented in Figure 2.
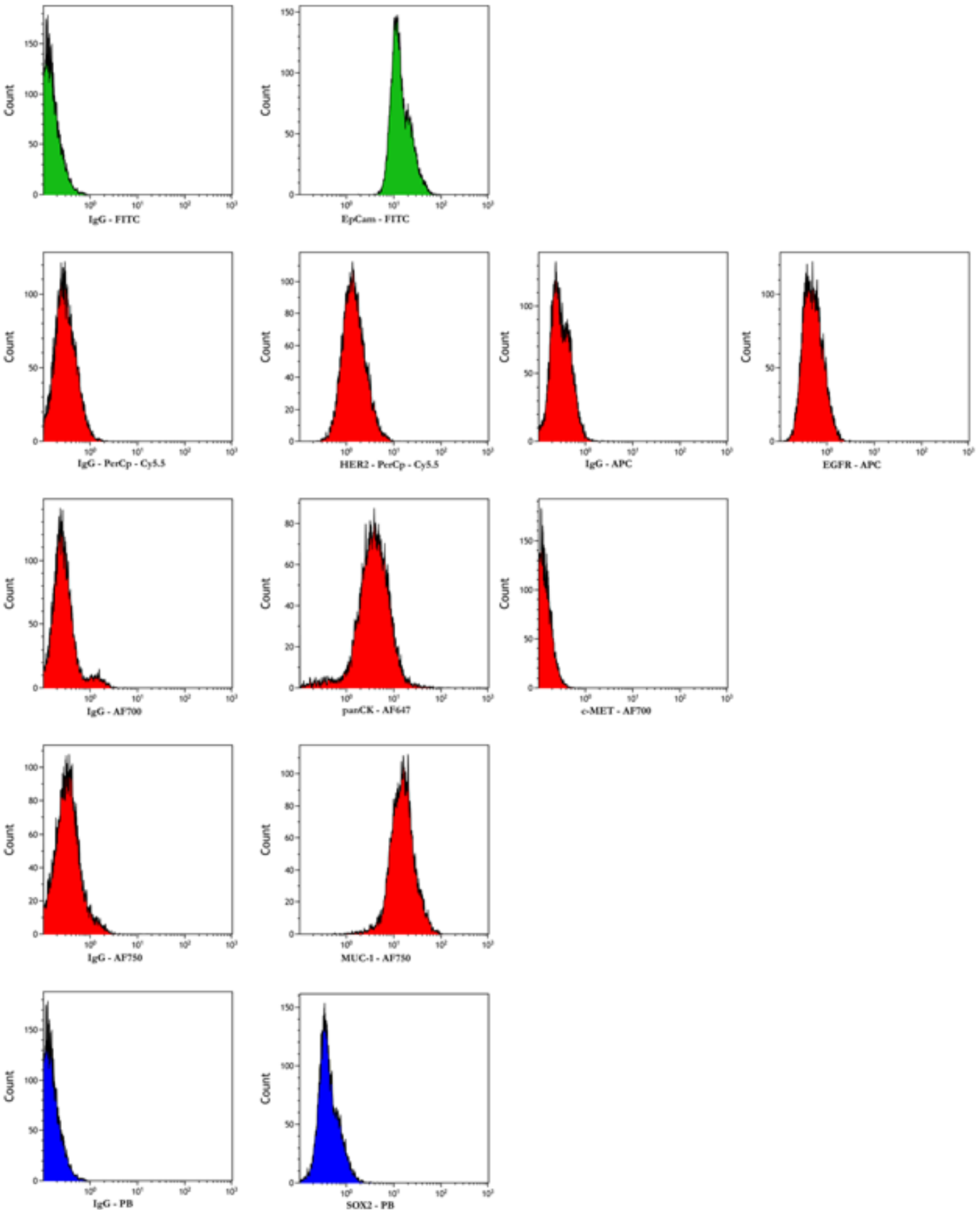

Figure 2.

Flow cytometry histograms of the HT-29 adenocarcinoma cells single stained with EpCAM-FITC, Her-2-PerCp Cy5.5, EGFR-APC, panCK-AF647, c-MET-AF700, MUC-1-AF750 and Sox-2-PB and their corresponding isotype controls

As shown in Figure 2, the flow cytometry analysis confirmed the confocal microscopy observations in terms of EpCAM and panCK expression as the intensity of their corresponding fluorochromes: FITC and AF647 were found increased as compared to the isotype control. In addition, we were able to identify by flow cytometry only, the expression of MUC-1 antigen on HT-29 cells.

In conclusion, based on both confocal microscopy and flow cytometry results, we decided to develop our detection protocol by using the EpCAM and panCK antigens. Additionally, considering that according to 
FARMACIA, 2018, Vol. 66, 5

the literature HT-29 cells express the MUC-1 antigen [28] and that we were able to detect it by flow cytometry, we decided to add this marker to our panel.

HT-29 adenocarcinoma cells isolation from peripheral blood samples by using EpCAM positive selection strategy

The cells isolated based on EpCAM positive selection strategy were analysed by flow cytometry in order to evaluate the efficiency of the HT-29 adenocarcinoma cells recovery from the peripheral blood. In this view, the isolated cells were labelled with antibodies against panCK, MUC-1, to highlight the population of interest and also with the CD45 antibody, to identify any

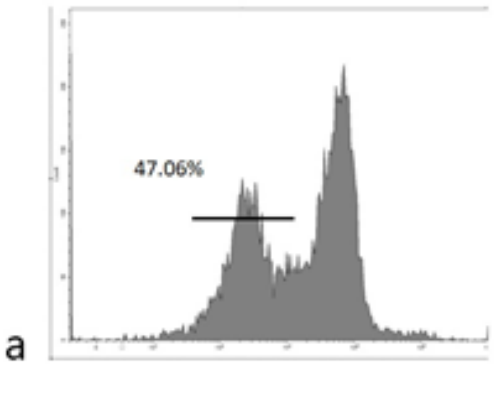

CD45-V500 potential residual blood cells specific population in the sample. The resulting Forward Scatter (FS)/Side Scatter (SS) and panCK/MUC-1 dot plot as well as the histogram corresponding to CD45 conjugated fluorochrome were presented in Figure 3.

The cells isolated from the peripheral blood by EpCAM positive selection strategy were distributed in two populations. Further analysis of these populations proved that one was positive for CD45 and one was negative for this marker. The CD45 positive population represents $47.06 \%$ from all the cells (Figure 3a). More, the CD45 negative population was found to be doubled positive for panCK and MUC-1 (Figure 3b).

Figure 3.

Flow cytometry diagrams of the cells isolated from peripheral blood using EpCAM positive selection strategy: a) CD45-V500 histogram and b) panCK-AF647/MUC-1-AF750 dot plot

HT-29 adenocarcinoma cells isolation from peripheral blood samples by using $C D 45^{+}$cells depletion as negative selection strategy

The cells isolated using the $\mathrm{CD} 45^{+}$depletion as a negative selection strategy were analysed by flow cytometry in order to evaluate the efficiency of the HT-29 adenocarcinoma cells recovery from the peripheral blood. In this view, the isolated cells were labelled with antibodies against EpCAM, panCK, MUC-1, to highlight the population of interest and also with the CD45 antibody, to identify any potential residual blood cells specific population in the sample. The resulting Forward Scatter (FS)/Side Scatter (SS) dot plot as well as the histograms corresponding to EpCAM, panCK, MUC-1 and CD45 conjugated fluorochromes were presented in Figure 4.

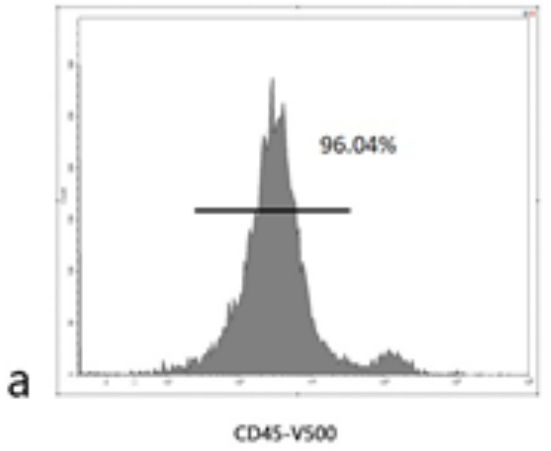

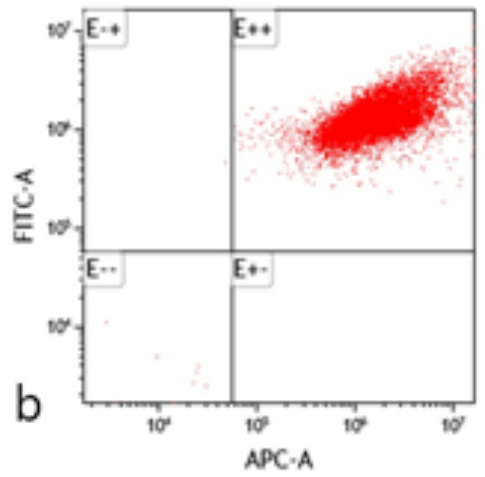

Figure 4.

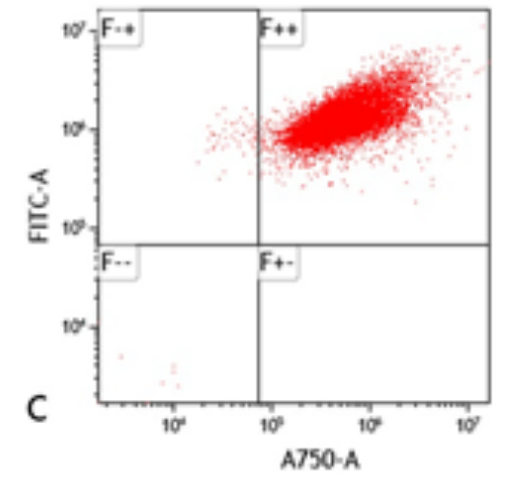

Flow cytometry diagrams of the cells isolated from peripheral blood by $\mathrm{CD} 45^{+}$depletion as a negative selection strategy: a) CD45-V500 histogram and b) EpCAM-FITC/panCK-AF647 dotplot, c) EpCAM-FITC/MUC-1AF750 dot plot

The cells isolated from the peripheral blood by CD45 depletion as a negative selection strategy were distributed in two populations, of which one positive for CD45 and one negative for CD45 (96.04\% out of all the cells in the sample). More, the CD45 negative 
population was found to be triple positive for EpCAM, panCK and MUC-1 (Figures 4b and 4c).

\section{Conclusions}

In our in vitro experimental model, we were able to validate the expression of EpCAM, panCK and MUC-1 markers in HT-29 adenocarcinoma cells. More, we were able to detect $47.06 \%$ panCK and MUC-1 double positive cells from the EpCAM positive population isolated by positive selection strategy from a peripheral blood sample containing HT-29 cells. Furthermore, following the colon adenocarcinoma cells spike into peripheral blood samples we were able to detect 96.04\% EpCAM, panCK and MUC-1 triple positive cells out of the cells population isolated by CD $45^{+}$ depletion as a negative selection strategy.

\section{Acknowledgement}

This research was financed by the UEFISCDI, through PH-III-P2-2.1-PTE-2016-0149/19PTETUMFLOW Grant.

\section{References}

1. Biankin AV, Piantadosi S, Hollingsworth SJ, Patient centric trials for therapeutic development in precision oncology. Nature, 2015; 526(7573): 361-370.

2. Tsiaoussis J, Vassilopoulou L, Nikolouzakis T, Rakitskii VN, Vakonaki E, Fragiadaki P, Stivaktakis P, Tsatsakis AM,. Biomolecular profile of colorectal cancer - the role of telomerase as a potent biomarker. Farmacia, 2017; 65(5): 643-659.

3. Ginghina O, Nitipir C, Colorectal Cancer - Diagnosis, Screening and Management. IntechOpen, 2018; Chapter 2: Liquid Biopsy for Colorectal Cancer Screening, A Modern Approach for Patients Stratification and Monitoring, 16-26.

4. Bettegowda C, Sausen M, Leary RJ, Kinde I, Wang Y, Agrawal N, Detection of circulating tumor DNA in early - and late - stage human malignancies. Sci Transl Med., 2014; 6(224): 224ra24.

5. Schwarzenbach H, Hoon DS, Pantel K, Cell - free nucleic acids as biomarkers in cancer patients. Nat Rev Cancer, 2011; 11(6): 426-437.

6. Raposo G, Stoorvogel W, Extracellular vesicles: Exosomes, microvesicles, and friends. J Cell Biol., 2013; 200(4): 373-383.

7. Alireza Aliabadi, Ahmad Mohammadi-Farani, Saeed Seydikangarshahi, Farahnaz Ahmadi, Discovery of 2-(1,3-dioxoisoindolin-2-yl)-n-phenylacetamide derivatives as probable 15-lipoxygenase-1 inhibitors with potential anticancer effects. Farmacia, 2017; 65(2): 268-274.

8. Mavroudis D, Circulating cancer cells. Ann Oncol., 2010; 21(Suppl. 7): vii95-vii100.

9. Pantel K, Alix-Panabières C, Circulating tumor cells in cancer patients: challenges and perspectives. Trends Mol Med., 2010; 16(9): 398-406.

10. Miller MC, Doyle GV, Terstappen LW, Significance of circulating tumor cells detected by the CellSearch
System in patients with metastatic breast colorectal and prostate cancer. J Oncol., 2010; 2010: 1-8.

11. Andree KC, van Dalum G, Terstappen LWMM, Challenges in circulating tumor cell detection by the CellSearch system. Mol Oncol., 2016; 10(3): 395-407.

12. Brinkmann F, Hirtz M, Haller A, Gorges TM, Vellekoop MJ, Riethdorf S, Muller V, Pantel K, Fuchs $\mathrm{H}$, A versatile microarray platform for capturing rare cells. Nat Sci Rep., 2015; 15342: 1-11.

13. Stott SL, Hsu CH, Tsukrov DI, Yu M, Miyamoto DT, Waltman BA, Isolation of circulating tumor cells using a microvortex-generating herringbone-chip. Proc Natl Acad Sci., 2010; 107(43): 18392-18397.

14. Okumura T, Yamaguchi T, Watanabe T, Nagata T, Shimada Y, Flow cytometric detection of circulating tumor cells using a candidate stem cell marker, p75 neutrotrophin receptor (p75NTR). Methods Mol Biol., 2017; 1643: 211-217.

15. Bhagwat N, Dulmage K, Pletcher JrCH, Wang L, Sen $\mathrm{M}$, An integrated flow cytometry-based platform for isolation and molecular characterization of circulating tumor single cells and clusters. Nat Sci Rep., 2018; $8(1): 1-14$.

16. Nicolazzo C, Raimondi C, Francescangeli F, Ceccarelli $\mathrm{S}$, Trenta P, Magri V, EpCam - expressing circulating tumor cells in colorectal cancer. Int J Biol Markers, 2017; 32(4): e415-e420.

17. Lu SH, Tsai WS, Chang YH, Chou TY, Pang ST, Lin $\mathrm{PH}$, Tsai CM, Chang YC, Identifying cancer origin using circulating tumor cells. Cancer Biol Ther., 2016; 17(4): 430-438.

18. Bednarz-Knoll N, Alix-Panabières C, Pantel K, Plasticity of disseminating cancer cells in patients with epithelial malignancies. Cancer Metast Rev., 2012; 23: 573-581.

19. Kang Y, Pantel K, Tumor cells dissemination: emerging biological insights from animal models and cancer patients. Cancer Cell, 2013; 23: 573-581.

20. Dienstmann R, Tabernero J, Spectrum of gene mutations in colorectal cancer: implications for treatment. Cancer J., 2016; 22: 149-155.

21. Jauhri M, Bhatnagar A, Gupta S, Shokeen Y, Minhas S, Aggarwal S, Targeted molecular profiling of rare genetic alterations in colorectal cancer using next generation sequencing. Med Oncol., 2016; 33: 1-8.

22. Spano JP, Lagorce C, Atlan D, Milano G, Domont $\mathrm{J}$, Benamouzig R, Impact of EGFR expression on colorectal cancer patient prognosis and survival. Ann Oncol., 2005; 16: 102-108.

23. Peeters M, Price T, Van Laethem JL, Anti-epidermal growth factor receptor monotherapy in the treatment of metastatic colorectal cancer: Where are we today? Oncologist, 2009; 14: 29-39.

24. Zeng Y, Zhang Q, Zhang Y, Lu M, Liu Y, Zheng T, Feng S, Hao M, Shi T, MUC1 predicts colorectal cancer metastasis: a systematic review and meta - analysis of case controlled studies. PLoS One, 2015; 10(9): $1-17$.

25. 25. Takahashi H, Jin C, Rajabi H, Pitroda S, Alam M, Ahmad R. Raina D, Hasegawa M, Suzuki Y, Tagde A, Bronson RT, Weichselbaum R, Kufe D, MUC1-C activates the TAK1 inflammatory pathway in colon cancer. Oncogene, 2015; 34: 5187-5197. 
FARMACIA, 2018, Vol. 66, 5

26. Zheng J, Xu L, Pan Y, Yu S, Wang H, Kennedy D, Zhang Y, Sox2 modulates motility and enhances progression of colorectal cancer via the Rho-ROCK signaling pathway. Oncotarget, 2017; 8(58): 9863598645.

27. Lundberg IV, Löfgren Burström A, Edin S, Eklöf V, Öberg A, Stenling R, SOX2 Expression Is Regulated by BRAF and Contributes to Poor Patient Prognosis in Colorectal Cancer. PLoS One, 2014; 9(7): e101957.

28. Syrkina MS, Rubtsov MA, Potashnikova DM, Kondratenko YD, Dokrunova AA, Veiko VP, Cell models for the investigation of the role of the mucin MUC1 extracellular domain in metastazing. Acta Naturae, 2014; 6(2): 62-70. 